\title{
Chemical Flooding in Naturally Fractured Reservoirs: Fundamental Aspects and Field-Scale Practices
}

\author{
B. Yadali Jamaloei \\ Department of Chemical and Petroleum Engineering, Schulich School of Engineering, University of Calgary, \\ 2500 University Drive NW, Calgary, Alberta, T2N IN4 - Canada \\ e-mail: byadalij@ucalgary.ca
}

Résumé - Inondation chimique dans les réservoirs naturellement fracturés : aspects fondamentaux et pratiques de plein champ - Des méthodes appropriées devraient être utilisées pour augmenter la récupération d'huile des réservoirs naturellement fracturés (RNFs). Un des candidats pour augmenter cette récupération d'huile de ces réservoirs est l'injection d'eau contenant des agents chimiques. Cet article met en lumière les résultats techniques et les défis de cette technique. La classification, les caractéristiques de production, les mécanismes de rétablissement du RNFs et les résultats significatifs de l'injection d'eau contenant des agents chimiques dans ces réservoirs sont passés en revue et analysés. Ce papier vise à être un outil de référence utile aux ingénieurs intéressés par l'injection d'eau contenant des agents chimiques dans les RNFs.

\footnotetext{
Abstract - Chemical Flooding in Naturally Fractured Reservoirs: Fundamental Aspects and Field-Scale Practices - Appropriate methods should be employed to enhance the oil recovery from the Naturally Fractured Reservoirs (NFRs). One of the candidates for enhancing the oil recovery from these reservoirs is the surfactant-based chemical flooding. This paper highlights the technical achievements and challenges of the chemical flooding in the NFRs. The classification, production characteristics, recovery mechanisms of the NFRs and significant findings of the chemical flooding in these reservoirs are reviewed and analyzed. It is expected that this paper will serve as a helpful reference tool for the engineers interested in chemical flooding in the NFRs.
} 


\section{INTRODUCTION}

NFRs are huge contributors to the world's oil reserves. These oil reservoirs are found in the Middle East, North Africa, North and South America, and the North Sea. Suitable methods have to be employed to enhance the oil recovery from these reservoirs. Surfactant-based chemical flooding processes have shown some promising results for enhancing the oil recovery from NFRs. However, proper implementation of the field-scale chemical flooding projects in NFRs is still a major challenge. The main reason is that the production characteristics of the NFRs fundamentally differ from those of the conventional reservoirs. This paper provides an in-depth evaluation of the technical achievements and challenges of the chemical flooding processes in NFRs. First, a brief technical background on the chemical flooding processes, classification of NFRs and their production characteristics, and the mechanisms of oil production in NFRs are provided. Then, fundamental aspects and case studies of the chemical flooding in NFRs are reviewed. Finally, significant findings of the fundamental studies, pilot trials, and commercial field projects of the chemical flooding in NFRs are analyzed.

\section{TECHNICAL BACKGROUND}

\subsection{Chemical Flooding as an Enhanced Oil Recovery Method}

The surfactant-based chemical flooding is a general term for the processes that inject surfactant-contained chemical solutions (or slugs) into the reservoir for enhancing the oil recovery. These processes aim at producing the trapped, residual oil after the waterflooding (Yadali Jamaloei and Kharrat, 2010a). The microemulsions, which are used to lower the Interfacial tension (IFT) between the displacing and displaced fluids, contain surfactant, hydrocarbon and water. Cosurfactant or an electrolyte may be added (Yadali Jamaloei and Kharrat, 2010b). The surfactant and/or an alkali are used in the injected chemical solution to reduce the IFT between the oil and water in the reservoir (Yadali Jamaloei et al., 2010b). Polymers may also be employed to improve the mobility ratio, and consequently, the displacement sweep efficiency (Yadali Jamaloei et al., 2010a). A tremendous amount of work has been published in the area of chemical flooding for enhancing the oil recovery. It is beyond the scope of this article to provide a review of all the published works. The author refers the reader to the comprehensive literature surveys on the various aspects of chemical flooding provided by Shah and Schechter (1977), Shah (1981), van Poollen (1981), Donaldson et al. (1989), Hirasaki (2008), and Yadali Jamaloei (2007, 2009). Meanwhile the author lists solely a brief classification of the chemical flooding processes and the factors affecting the oil recovery performance via these processes.
Micellar-polymer and alkaline flooding are regarded as the two major chemical flooding processes. Micellar flooding (also known as microemulsion flooding or surfactant flooding) is a process in which a surfactant slug is injected into the formation followed by a larger slug of water containing polymer. Besides this classification, different forms of surfactantbased chemical flooding processes have been reported in the literature, namely:

- alkali-surfactant-polymer flooding (Daoshan et al., 2004);

- surfactant-polymer flooding also known as low-tension polymer flooding (Yadali Jamaloei et al., 2011b);

- alkali-surfactant flooding (Liu et al., 2006);

- dilute surfactant flooding (Krumrine, 1982).

The traditional injection scheme for a surfactant-based chemical flooding process includes injecting a preflush, a chemical solution, a mobility buffer, and finally, a driving fluid, which displaces the chemicals and the developed oil bank towards producer (Yadali Jamaloei, 2009). It should however be noted that the modern surfactants have made it possible to design formulations for the injected chemical solution without the need for a preflush.

\subsection{Factors that Influence the Chemical Flooding}

Many factors influence the behavior of surfactant-based chemical flooding processes. These factors include the surfactant types (Hayes et al., 1979), chemistry (Enedy et al., 1982; Hirasaki et al., 1983; Krumrine et al., 1982), phase behavior (Glover et al., 1979; Novosad, 1982), chemicals adsorption (Austad et al., 1997), surfactant precipitation and redissolution (Somasundaran et al., 1984), chromatographic separation of chemicals (Li et al., 2009), surfactant convection (Ramirez et al., 1980), surfactant stability (Handy et al., 1982), chemicals loss (Friedmann, 1986), dispersion (Hirasaki, 1981), surfactant systems formulation (Salager $e t$ al., 1979), wettability (Dong et al., 2006; Yadali Jamaloei and Kharrat, 2010a), reservoir rock structure and morphology (Dullien et al., 1972; Yadali Jamaloei and Kharrat, 2009; Yadali Jamaloei et al., 2011a), and reservoir heterogeneity (Ma et al., 2007). The morphology and heterogeneity of the reservoir rock play a significant role in the behavior of chemical flooding processes. In fact, the geology of the reservoir is considered as the foremost parameter, which influences the oil recovery (Morrow, 1990). The role of the reservoir rock geology is more significant in NFRs as these reservoirs normally possess a very heterogeneous nature.

\subsection{Naturally Fractured Reservoirs}

\subsubsection{Definition and Classification}

NFRs are very important contributors to the world's oil and gas reserves (Nelson, 1985). According to Firoozabadi (2000), approximately one-fifth of oil reserves lies in NFRs. 
Bourbiaux (2010) argues that this ratio may fluctuate in different references because the classification of a reservoir as NFR is often not straightforward. Nevertheless, the typical theme in all these reservoirs is that they are generally understood as unconventional reservoirs with low porosity and high permeability. Bourbiaux (2010) has discussed the typical geological settings of the fractured reservoirs in detail by providing the well-known examples of NFRs worldwide. The common basic element in all NFRs is the presence of porous blocks, called the matrix, and of a connected network of fractures. This common element has been expressed in all the dual-porosity models in the literature. Barenblatt et al. (1960) and Warren and Root (1963) are the pioneers to use this dual-porosity approach in order to simulate the flow behavior and to model the transient well test responses of NFRs. To evaluate NFRs, one should integrate the geologic models, logs, cores, outcrops, and well testing (Aguilera, 1987). Various models of geometrical properties of the matrix and connectivity of the fracture network have been reported by Aguilera (1995). Due to the flow complexity in fractures, the transient behavior in the NFRs has not been understood completely, particularly in multi-layered NFRs (Aguilera, 2001). The modelling of this type of flow is normally based on the porous medium approach, pipe flow model and the equivalent homogeneous single-phase model (Shad and Gates, 2010).

The geological characterization of a NFR is feasible once the nature of fractures distribution is known (Nelson, 1985). The network of fractures can be a continuous flow path throughout the reservoir (Saidi, 1983). Moreover, fractures with different geometries and scales may be present in the network (Wu et al., 2004; Gasem et al., 2008). Various models in the literature show the means of estimating the petrophysical properties of NFRs. For instance, according to Aguilera and Aguilera (2009), for dual and triple porosity reservoirs, the system can be modelled as a parallel resistance network (for matrix and fractures), a series resistance network (for matrix and non-connected vugs) or a combination of parallel/series resistance networks (for matrix, fractures and non-connected vugs). Generally, NFRs can be classified into four categories (Allan and Qing Sun, 2003):

- NFRs in which fractures act as storage capacity and flow pathways;

- NFRs in which matrix provides some storage capacity and fractures are the flow pathways;

- NFRs in which matrices are storage capacity and fractures act as flow conduits;

- NFRs in which matrices act as storage capacity and flow pathways.

It is worth noting that other classifications for NFR are available in the literature (see for instance the classifications reported in Van Golf-racht (1982), Nelson (1985), Aguilera (1995), and Bourbiaux (2010)).

\subsubsection{Production Characteristics}

Babadagli (2001a) has summarized the foremost oil production features and mechanisms in NFR, which are different from those in the conventional reservoirs. According to Babadagli (2001a), the production in NFRs is governed by mutual interaction between the matrix blocks and the fractures. To be precise, fluid expansion, gravity drainage, and imbibition buttress the fluid flow into the fractures. Usually, the pressure drop around a producing well is very low in those NFRs with some matrix permeability. Thus, pressure gradient does not play a vital role in the oil production. Also, the gas-oil ratio in NFRs is typically lower than that in the conventional reservoirs, provided that the reservoir is appropriately managed. Moreover, due to the paucity of the transition zones in most NFRs, oil-water and gas-oil contacts are knife-sharp surfaces. As a result of the convective circulation over the production life of a highly-fractured reservoir, the PVT properties generally do not change throughout the reservoir. For instance, unlike conventional reservoirs, in a highly-fractured reservoir the bubble point does not vary as a function of depth within the oil column. According to Saidi (1987), the bubble point pressure depression in a highly-fractured reservoir can be indicated by a continuous drop in the produced gas-oil ratio. Finally, in some NFRs the rock and PVT properties have insignificant effect on the water production (Babadagli, 2001a). Further details on the multiphase flow in the fractures, relative movement of oil/water and gas/oil contacts, localized deformation of fluid contacts (i.e., coning), production decline analysis, and pressure and production tests can be found in Reiss (1980), Van Golf-racht (1982), Saidi (1987), and Da Prat (1990). In particular, the application of existing models to field cases, and the evaluation and description of NFRs, based on processed data from pressure and production tests have been discussed in detail by Da Prat (1990).

\subsubsection{Production Mechanisms and Recovery Processes}

Matrix recovery in a NFR is achieved by an interaction between the fluid in fracture and the matrix oil. Fracture fluid acts as a force displacing the matrix oil out of matrix by viscous displacement, mass transfer or capillary displacement. The type of displacement is determined by the properties of the rock matrix and fluids (Babadagli, 2001a). Depending on the matrix size, wettability and fracture orientation, which determine the amount of threshold pressure to be exceeded for an interaction, gravity drainage may become the dominant recovery mechanism (Babadagli, 2002).

Several production mechanisms have been proposed to work in NFRs. According to Lemonnier and Bourbiaux (2010a), numerous sensitivity runs are required in order to identify the main recovery mechanisms existing in a NFR. Saidi (1987) has documented most of our present understanding of the mechanisms in the highly-fractured reservoirs. 
According to Saidi (1987), one of the foremost features in a highly-fractured reservoir is the block-to-block process, which involves the gravity drainage of a variable volume of oil from the upper to the lower blocks. Hence, these reservoirs should be produced under full gravity drainage (and/or imbibition) to achieve the highest oil recovery from the low permeability matrix rocks. Another important mechanism in NFRs is the solution gas drive mechanism (Saidi, 1987). The theory of solution gas drive mechanism is based on the relationship between supersaturation pressure, diffusion, rate of pressure drop, gas-oil IFT, pore diameter and the pore size distribution of the matrix blocks.

The recovery processes and the main drive mechanisms involved in the primary, secondary, and tertiary recovery processes in NFRs have been described in a comprehensive work by Lemonnier and Bourbiaux (2010a). Therefore, here only a very brief description regarding the recovery processes in NFRs is provided and the reader in referred to the work of Lemonnier and Bourbiaux (2010a) for further details. In summary, regarding the primary and secondary recovery processes (i.e., solution gas drive, gas injection, and waterflooding), the presence of a capillary continuity in a NFR has a profound influence on the ultimate oil recovery. In other words, the existence of a capillary continuity between the blocks and an efficient fractures-matrix blocks exchange are essential for the effectiveness of the gas cap expansion, waterflood, and gasflood (Lemonnier and Bourbiaux, 2010a). In regard to the enhanced oil recovery processes, experience has shown that gas injection, water-alternating-gas injection, chemical flooding, and thermal methods can be deployed for recovering the residual oil after waterflooding in NFRs. The main reason is that after waterflooding, a large fraction of the oil may be trapped both at the pore scale and in the bypassed zones at the macro scale. Among all the tertiary recovery methods, gas injection in NFRs has largely been practiced in the pilot and field scales (Yadali Jamaloei and Kharrat, 2011; Lemonnier and Bourbiaux, 2010a). Further details on the expansion and sudation mechanisms, convection/diffusion, and the interplay of different recovery processes during primary, secondary, and tertiary productions can be found in Reiss (1980), Van Golf-racht (1982), and Saidi (1987).

\subsubsection{Simulation and Modeling of Fluid Flow}

Numerical simulation is an indispensable part of reservoir engineering and management throughout the entire life of a NFR. The significance of numerical simulation lies in that it enables us to forecast the response of a NFR to a variety of recovery scenarios. Thank to the several decades of intensive research on the dual-porosity models, which was pioneered by Barenblatt et al. (1960) and Warren and Root (1963), for simulating the flow behavior in NFRs, these models have become the backbone of all the available industrial NFR simulators. Building a dual-porosity model that best fits the hydraulic behavior of the actual NFR is the first step in constructing a robust simulation model. This is achieved by parameterizing the dual-porosity model for which the equivalent fracture permeabilities and the equivalent matrix block dimensions should properly be identified (Bourbiaux et al., 1998).

For a comprehensive review of the simulation and modeling of fluid flow in NFRs, the reader is referred to the works of Lemonnier and Bourbiaux (2010a, b). In their works, a history of the development of NFR simulators, the essential features of dual-medium simulators, simulation of specific phenomena in fractures and conductive faults, modeling of matrix-fracture transfers and geomechanics effects, and quantification of uncertainties have extensively been addressed. Thus, the focus here is to briefly point out some of the progress that has been made in the modeling of fluid flow in the NFRs since the 1970s.

Modeling the effect of matrix-fissure transfer and the instability of a density inversion on the convection in vertical fissures has been the focus of early studies conducted by Peaceman (1976a, b). Also, a considerable amount of research has been devoted to the modeling of water-oil flow and also simulation of NFRs with semi implicit source terms. Particular examples of such studies are those of Kazemi et al. (1976) and Rossen (1977). In the 1980s, some studies have investigated the modeling of the steady flow in the networks of disc-shaped fractures (Long et al., 1985), viscous and gravity displacement in matrix blocks (Gilman and Kazemi, 1988), and gas-oil drainage and water-oil imbibition (Rossen and Shen, 1989). Finally, the focus of numerous works in the 1990s and 2000s has been the modeling of diffusive transport and natural convection in fractured media (Ghorayeb and Firoozabadi, 2000; Landereau et al., 2001), matrix-fracture transfer functions (Kazemi et al., 1992; Sarma and Aziz, 2006; Lu et al., 2008), and matrix-fracture transfer shape factors (Lim and Aziz, 1995). A general concluding remark is that a considerable progress has been made in the modeling of matrix-fracture exchange since the 1970s. Further details on the simulation and modeling of fluid flow in NFRs can be found in Reiss (1980), Van Golf-racht (1982), Gilman and Kazemi (1983), Saidi (1983, 1987), Da Prat (1990), Firoozabadi and Thomas (1990), and Lemonnier and Bourbiaux (2010a, b).

\section{CHEMICAL FLOODING IN NFRS}

\subsection{Motivations}

Waterflooding of NFRs under favorable conditions acts effectively. These favorable conditions include the presence of water-wet matrix and injection of enough amount of water into the fracture network. Although some experiments have shown that the waterflood performance in the water-wet and intermediate-wet fractured chalks may be nearly independent 
of wettability state (Tang and Firoozabadi, 2000), the general perception is that under favorable water-wet condition, capillary imbibition significantly improves the oil recovery (Babadagli, 2001a). An important type of capillary imbibition is the spontaneous imbibition, which involves both cocurrent and countercurrent flows in proportions depending on the ratio of gravity-to-capillary forces and on the existing conditions at the matrix boundaries (Bourbiaux and Kalaydjian, 1990). Rock properties such as matrix permeability, size and shape, wettability, heterogeneity, and boundary conditions control the capillary imbibition. Moreover, properties of the imbibing water, viscosities of the phases, and IFT affect the capillary imbibition recovery rate. However, unfavorable conditions may exist in some NFRs. These include the presence of heavy-oil, oil-wet matrix, the limiting matrix boundary conditions, large matrix sizes, low matrix permeability, and high IFT, all of which could hamper the normal dynamics of oil displacement. In such unfavorable cases, waterflooding fails to properly work and additional measures are required to enhance the oil recovery in NFRs. Injecting surfactant solution to reduce the IFT, and/or adding polymer to the injected water to confront with existing high mobility contrast are the two possible measures (Babadagli, 2001a). Thus, chemical flooding of a NFR is generally concerned with the influence of surfactant/alkali and polymer on the dynamics of oil displacement.

\subsection{Fundamental Aspects}

\subsubsection{Production Features and Recovery Mechanisms}

A large quantity of world's oil reserves is contained in carbonate reservoirs (Roehl and Choquette, 1985). Most of these reservoirs are naturally fractured. The fracture network normally has much higher permeability than that of porous matrix, accounting for poor primary oil recovery. Waterflooding can be an effective method for the improvement of oil recovery from water-wet NFRs, where spontaneous imbibition of the injected water is the main recovery mechanism. However, majority of the carbonate rocks are mixed-wet to preferentially oil-wet (Downs and Hoover, 1989), which are unfavorable conditions for the spontaneous water imbibition.

As it was mentioned above, spontaneous imbibition solely occurs when the pores are preferentially water-wet. Thus, water imbibes into the rock matrix, and oil is expelled into the fractures where it is displaced through the fractures toward the production wellbore (Weiss and Xie, 2007). The results of the experiments conducted by Babadagli (2001b) have revealed the conditions under which the capillary imbibition can be enhanced in the matrix containing the heavy oil. He conducted polymer, surfactant, and hot water injection to recover the heavy-matrix oil via capillary imbibition for different matrix and oil properties (using water-wet
Berea sandstones containing heavy oils and oil-wet carbonate cores containing light oils). The results show that all the three methods (i.e., polymer, surfactant, and hot water flooding) result in higher and faster capillary imbibition recovery relative to that of waterflooding. Furthermore, the influence of chemical additives and high temperature of water is more profound on the ultimate recovery than the recovery rate for the higher-viscosity oils.

The spontaneous imbibition does not occur if rocks are oil-wet or neutral-wet. Under such conditions, a dilute anionic surfactant solution can be injected into the oil-wet NFRs whereby surfactant enters the matrix, and lowers the IFT and contact angle. Anionic surfactants are known to change the wettability of the carbonate surfaces to intermediate/water-wet, which lowers the contact angle (Najafabadi $e t$ al., 2008). Therefore, one explanation of improved recovery by surfactant solutions is the reduction in IFT/contact angle and the increase in oil relative permeability, enabling gravity to drain up the oil. Other explanation of improved recovery by imbibition of surfactant solutions is the release of the adsorbed organic materials from the pore surfaces, making them more water-wet. This increases the imbibition rate (Weiss and Xie, 2007). The transport mechanism for the surfactant to get far into the matrix for changing the wettability and/or lowering the IFT has been debated in the literature. Recently, Abbasi-Asl et al. (2010) have attempted to address this fundamental issue. Their simulation results show that even very small pressure gradients (transverse to the flow in the fractures) promote the surfactant transport into the matrix at a feasible rate even in the presence of a significant contrast between the permeability of the fractures and the matrix.

Another explanation for the improved oil recovery by surfactant is that the surfactants lower the capillary pressure. The latter increases the Bond number (ratio of gravitationalto-capillary forces), which improves the recovery via gravity segregation (Weiss and Xie, 2007). Gravitational forces overcome the entry capillary pressure and water invades the matrix and pushes the oil out. This is called the surfactantaided gravity drainage. In this process, the key to recovering the oil is the wettability alteration to preferentially water-wet or intermediate-wet state (Adibhatla and Mohanty, 2006). The rate of oil recovery from initially oil-wet NFRs via a gravity-driven process increases by an increase in IFT provided that the wettability can be shifted towards preferentially water-wet state. The increase in the extent of wettability alteration towards water-wet condition, temperature, and the fracture density has been reported to increase the rate of oil recovery from initially oil-wet NFRs via a gravity-driven process (Gupta et al., 2009). In another study, Adibhatla and Mohanty (2006) have demonstrated that in surfactant-aided gravity drainage, the rate of oil recovery increases with an increase in matrix permeability, a decrease in initial gas saturation, a decrease of fracture height or spacing, and an increase in the capabilities of the surfactant for the wettability 
alteration. In regard to the screening of the surfactant for the wettability alteration in oil-wet fractured carbonates, Gupta $e t$ al. (2009) have identified surfactants capable of changing the contact angle of an initially oil-wet calcite plate in the presence of low temperature-low salinity, high temperature-low salinity, low temperature-high salinity and high temperaturehigh salinity. This proves that surfactants can be used to alter the wettability of oil-wet fractured carbonates under a variety of temperature and salinity conditions.

In order to better understand the mechanisms of the oil recovery from the initially oil-wet matrix surrounded by surfactant solution under conditions of ultra-low oil-water IFT, the effect of the capillary and gravitational forces is explained here. In order for the water to enter an oil-wet matrix to push out, the oil the entry capillary pressure must be exceeded. When the initially oil-wet matrix is surrounded by water at hydrostatic pressure, buoyancy causes an upward displacement of the oil. The main challenge is that this action of buoyancy can become limited due to the presence of a negative capillary pressure in the initially oil-wet matrix blocks. The principal function of the surfactant solution surrounding the matrix block is to lower the IFT (or the entry capillary pressure). Consequently, the surfactant solution is now capable of entering the matrix by replacing the oil that is displaced by the buoyancy. One can therefore conclude that the capillary pressure gradient does not contribute to the oil recovery in the presence of ultra-low IFT and/or the shifted wettability towards the neutral state. Thus, under the abovecited circumstances, the oil flux is significantly influenced by the density difference between the oil and water, gravitational acceleration, matrix block permeability, relative permeability, and oil viscosity as long as the water pressure is hydrostatic. Among the mentioned factors, the oil relative permeability is influenced by the oil saturation, pore morphology of the matrix block, pore wettability, and the Bond number. The Bond number (which itself is a function of the matrix block permeability) governs the distribution of the residual oil saturation in the presence of buoyancy. Hence, the Bond number requires that the IFT be ultra-low to avoid trapping of the oil especially for the matrix blocks with the lower permeability. Further details on the influence of capillary, viscous, and buoyancy forces on the phase mobilization and trapping can be found in Morrow and Songkran (1981), Van Golf-racht (1982), Saidi (1987), and Penell et al. (1996).

In addition to the discussion in previous paragraphs, Adibhatla et al. (2005) argues that in some cases both capillarity and gravity cause improvement in the oil production from the initially oil-wet matrix blocks by alkaline surfactant imbibition. Their simulation model validated using the experimental data of alkaline surfactant imbibition in the initially oil-wet matrix blocks indicates that the capillarity is the major driving force during the early stage of the production whereas gravity becomes the dominant factor influencing the oil recovery during the later stage. In this case, oil mobilization occurs as a result of IFT reduction and wettability alterations both of which are the consequences of surfactant transfer into the matrix blocks. Also, the reported simulation results illustrate that the rate of oil production from the initially oil-wet matrix blocks by alkaline surfactant imbibition decreases by the decrease in matrix permeability and degree of wettability shift towards water-wet state, and the increase in matrix block height.

Recently, natural imbibition under conditions of ultra-low oil-water IFT (i.e., lower than $10^{-2} \mathrm{mN} / \mathrm{m}$ ) with anionic surfactants have been reported by Hirasaki and Zhang (2004), Seethepalli et al. (2004), Abidhatla and Mohanty (2006), and Zhang (2007). Obviously, the contribution of capillary forces to the natural imbibition is not significant under the ultra-low oil-water IFT. Instead, under such conditions, the oil displacement during natural imbibition is influenced by the predominance of buoyancy and wettability alteration (Hirasaki and Zhang, 2004). Furthermore, most surfactant solutions tested by Abidhatla et al. (2005) formed a microemulsion in the imbibition experiments, which was indicated in the phase behavior tests. This process is called the emulsification-driven natural imbibition (Zhang et al., 2008). Zhang et al. (2008) reported that in the emulsification-driven natural imbibition, the formation of microemulsion and/or emulsion and buoyancy is mainly responsible for the oil mobilization; they have considered the wettability alteration as an ensuing effect. Also, as the IFT between the oil and microemulsion is very low and inversely proportional to the solubilization ratio (Huh, 1979), the availability of surfactant for emulsification is crucial. Hence, methods should be employed to reduce the surfactant consumption. Zhang (2007) suggests using alkalis such as sodium carbonate so as to reduce the amount of synthetic surfactant required for the effective, low-IFT oil mobilization. The reason is that the alkalis have the ability to reduce surfactant adsorption and generate in-situ natural soap. The former effect is particularly important for the use of anionic surfactants in the carbonate reservoirs.

Finally, in NFRs, if the objective is to effectively recover the oil in the matrix, the ultimate oil recovery should be the target. Alternatively, if, the objective is to increase the production rate, one should focus on the increase in the recovery rate rather than the ultimate oil recovery. Carbonate heavy oil fields with low recovery factor are good candidates for this type of strategy. Gupta and Mohanty (2008) have shown that wettability alteration can be effective in increasing the oil recovery rate from the fractured carbonates. Also, gravity dominantly affects the matrix-fracture interaction due to a greater matrix size, less water-wet attribute, and a lower IFT. The latter can be achieved using methods such as surfactant and heat injection especially in carbonate heavy oil fields. This reduces the capillary imbibition rate and makes the gravity effects dominant in the matrix-fracture interaction (Babadagli, 2001a, 2002; Allan and Qing Sun, 2003; Zhang et al., 2006). 


\subsubsection{Major Physicochemical Phenomena}

The physicochemical interactions in chemical flooding of NFRs have extensively been evaluated in the literature. An important aspect of the carbonate formations is that they are mostly positively charged; hence, nonionic and cationic surfactants should be used to reduce the surfactant adsorption. Some cationic surfactants have been reported to prevent the creation of ultra-low oil-water IFT as a result of which the capillary forces would still govern the imbibition process. In other words, some cationic surfactants can alter the wettability in the presence of IFT ranges in which counter-current imbibition still dominates the recovery mechanism. The alkali such as sodium carbonate can also be used to reduce the adsorption of sulfonate surfactants (Najafabadi et al., 2008). Hirasaki and Zhang (2004) have explained this behavior. They found that positively charged calcite surface can become negatively charged in the presence of sodium carbonate, which consequently reduces the adsorption of some anionic surfactants.

Natural imbibition in carbonate and dolomite cores with nonionic surfactants has been studied by Babadagli (2001a), Chen et al. (2000), and Xie et al. (2005). All of these works concluded that the use of some nonionic surfactants under certain conditions (such as certain temperature ranges) results in higher capillarity driven natural imbibition rates than that using ionic surfactants. They have attributed this behavior to the higher oil-water IFT created by nonionic surfactants. It is however worth noting that Adibhatla and Mohanty (2006) have illustrated that the ultra-low IFT may result in faster oil recovery by buoyancy driven displacement and higher ultimate oil recovery. Also, several experiments of natural water imbibition in initially mixed-wet to oil-wet chalk cores with different cationic and anionic surfactants were conducted by Standnes and Austad (2000). They reported that cationic surfactants exhibit a stronger wettability shift than anionic surfactants. The reason is that the cationic surfactants form ion pairs with adsorbed organic carboxylates of the crude oil, and solubilize them into the oil. Consequently, the rock surface wettability strongly shifts towards the preferentially waterwet state. This wettability alteration can lead to the countercurrent imbibition of brine, and thus, to the improved oil recovery. Finally, Tweheyo et al. (2006) and Zhang et al. (2006) reported that some divalent ions such as $\mathrm{Ca}^{2+}, \mathrm{Mg}^{2+}$ and $\mathrm{SO}_{4}{ }^{2-}$ can enhance the imbibition of cationic surfactant solutions in outcrop chalk cores. However, the presence of these ions at relatively high concentration is not favorable due to their potential precipitation with other ions such as carbonates and barium, which can exist in the injected and/or formation brines.

Adibhatla and Mohanty (2006) have explained the reason behind wettability alteration when anionic surfactants are used. According to Adibhatla and Mohanty (2006), anionic surfactants can remove the adsorbed organic carboxylates from the solid surface by solubilizing them in micelles because of the hydrophobic effect. Thus, the shift towards preferentially water-wet or intermediate wettability takes place, which increases the oil relative permeability. Moreover, the oil recovery from the fractured, initially oilwet carbonates via wettability alteration with dilute surfactant and electrolyte solutions has been discussed in detail by Gupta and Mohanty (2008). They have shown that the extent of wettability alteration increases by an increase of ethoxylation in anionic surfactants. Their results also suggest that an optimal surfactant concentration for varying salinity and an optimal salinity for varying surfactant concentration may exist at which the maximum wettability alteration can be attained using the anionic surfactants.

\subsubsection{How to Improve the Sweep Efficiency and Overcome the Heterogeneity}

Perhaps, the most effective method to improve the displacement sweep efficiency of chemical flooding in NFRs is the in-depth conformance control. Different kinds of chemicals are normally used to perform profile modification and conformance control. According to Llave and Dobson (1994), the conformance control modifies the permeability in highly-permeable zones, which improves the sweep efficiency. It also reduces the permeability contrast and diverts the primary drive fluid to the targeted zones. This is due to natural tendency of the media to chromatographically separate the components of the blends. Problems such as severe permeability contrast in the matrix and small scale fractures can be treated using conformance control. Llave and Dobson (1994) reported a field test in Stone Bluff Field, Oklahoma, which was conducted to evaluate the surfactant/alcohol-based conformance control. The alcohol component separated and propagated faster, leaving behind the bulk of the surfactant to form the viscous permeability barrier. Rock matrix contact is one of the primary mechanisms by which the surfactant/alcohol components separate and form the permeability barrier.

Another alternative for improving the displacement sweep efficiency of chemical flooding in NFRs is reducing the flow through the natural fractures. This can be done by applying a combination of cationic and anionic polyacrylamides (i.e., ploymers), and aluminum citrate as the cross-linker (Hochanadel and Townsend, 1990). Cationic polyacrylamide is injected first and enters the path of least resistance, i.e. natural fractures, and adsorbs onto the reservoir rock. This is followed by the addition of anionic polyacrylamide, which attaches to the cationic polymer, forming resistance to flow. This resistance diverts some of the injection into previously unswept portions. Aluminum citrate is added to crosslink the polymer molecules, forming a colloidal dispersion gel, which creates a greater resistance to flow. This method was successfully tested in Newcastle Sand Unit and improved the chemically-enhanced waterflood performance (Hochanadel and Townsend, 1990). 


\subsection{Pilot and Field Projects}

Surfactant, polymer, alkali, and their combinations can be considered as candidates to improve the recovery from some of the geologically challenging reservoirs. In particular, surfactant-based chemical flooding can be economically attractive for reservoirs in which the gravity and imbibition processes play a significant role in recovering the oil. Ideally, massive NFRs with $30-50 \%$ recovery may guarantee consideration for the surfactant-based chemical flooding with potential for either continuous injection or huff-n-puff application (Yang and Wadleigh, 2000). Furthermore, Yang and Wadleigh (2000) explain that in reservoirs with the gravity stabilized reservoir management some of the chemical flood conformance challenges of classic applications can be minimized.

Before explaining the pilot and field project of the chemical flooding in the NFRs (conducted mostly in the fields in North America), it would be beneficial to briefly list some of the foremost challenges that dictate the success of the fieldscale oil mobilization via surfactant-based chemical flooding in the NFRs either in huff-n-puff or continuous injection mode. Yang and Wadleigh (2000) has documented these foremost challenges as:

- circulating optimum concentration of the surfactant in water into the fractures;

- transferring the surfactant from fractures into matrices and less-connected fractures;

- displacing the oil from the matrix into the fractures; and capture of oil from the fracture network.

Therefore, in order to optimize the design of a surfactantbased chemical flooding process in the NFRs either in huffn-puff or continuous injection mode, the effects of various parameters including the surfactant injection rate, injection volume, chemical diffusion, convection, and fracture properties should thoroughly be examined on the fracture surface area treated and the penetration depth of surfactant solution into the matrix block (Yang and Wadleigh, 2000). In the following paragraphs, the pilot/field projects of the chemical flooding in the Mauddud Reservoir (Bahrain), Stone Bluff Field (Oklahoma), Townsend Newcastle Sand Unit (Wyoming), Big Horn Basin (Wyoming), and North Burbank Unit Block (Oklahoma) are reviewed.

Zubari and Sivakumar (2003) reported the results of several single-well tests to determine the efficiency of AlkalineSurfactant (AS) injection in Mauddud carbonate reservoir, which is a highly oil-wet heterogeneous limestone reservoir with fractures and vugs. Production from Mauddud was started in 1932. Crestal gas injection has been performed in this field for the pressure maintenance for 65 years. There has also been a natural aquifer support at the flanks. Expanding gas cap and water influx have influenced the recovery over the years. Due to oil-wetting nature, a very high water cut of
98-99\% has been reported. So, to reduce the water cut and improve the oil production, pilot trials were conducted using cross linking gels. Also, wells were treated with surfactant washes, diesel and xylene. Although successful, the wells returned to the original water cuts shortly. However, this indicated that using chemical treatments can strip more oil. Hence, it was decided to conduct a wettability-shifting process such as chemical flooding. The main challenge of chemical flooding in Mauddud is the difficulty of uniform sweep due to presence of fractures and vugs. Single well huff-n-puff AS floods were carried out in different wells in the flank areas, which are under the active water influx. The treatment was conducted in one well using a mixture of a 0.5 wt.\% surfactant in diesel. The water cut dropped and the oil production was doubled. However, the recovered oil was due to the stripping of oil and not wettability alteration. Xylene surfactant treatment in another well was carried out using xylene and mutual solvent. This treatment reduced the water cut. Again, the water cut returned to $98 \%$ shortly. However, the increased surfactant volumes had resulted in a more sustained wettability change and a longer period of stability in water cut. AS flood was conducted in another well with injection of $1 \mathrm{wt} . \%$ aqueous sodium carbonate solution. Oil rates increased marginally and stabilized back to the pretreatment levels shortly. In summary, an additional 15\% increase in oil recovery with the alkali treatment and additional 5\% with the diesel wash was obtained. Thus, the well treated with xylene-surfactant was AS flooded for wettability alteration using $1 \mathrm{wt} . \%$ aqueous sodium carbonate solution followed by $0.5 \mathrm{wt} . \%$ surfactant solution. Again, the water cut dropped and then stabilized back to $98 \%$. As a result, $5-15 \%$ of the oil were stripped across the well perforations, which shows that most of the dislodged oil had been dissipated into the formation. Finally, different surfactants with smaller slug sizes were tested in AS trial in another well. The treatment involved the injection of $1 \mathrm{wt} . \%$ alkaline solution followed by $0.5 \mathrm{wt} . \%$ surfactant solution. The results showed that unlike the earlier tests with larger slug sizes, the oil stripping was lower (about 5-10\%). One conclusion from these field trails is that AS flooding can recover a significant amount of the residual oil if the slug size is optimized.

Llave and Dobson (1994) explained a field test in Stone Bluff Field, Oklahoma. The purpose was to evaluate the surfactant/alcohol-based conformance control to improve the sweep efficiency. To improve the production, gas injection from 1926 until 1942, and natural gas pressure maintenance from 1942 to 1965 were conducted in the Field. Then, a waterflood was begun in 1987 and the oil production increased by mid-1989. To perform the test, the optimal parameters such as slug formulation (component ratio of 1:2, surfactant: alcohol), slug concentration (as high as $2 \mathrm{wt} . \%$ surfactant without any injectivity problems), and slug size were determined. The pressure fall-off test determined the rate at which the wellhead pressure bottoms out upon shut-in. 
This rate determines the type of down-hole problem when fractures are involved. The temperature survey showed that majority of the injected water would flow through the high permeability zones. Also, the tracer tests and pressure fall-off tests showed that the down-hole problems due to the smallscale fractures may arise. To conduct the test, the injected slug was followed by water injection. Prior to treatment, each of the wells had water cuts of $99-100 \%$. The post-treatment results reduced the water cuts for all wells to $96-98 \%$. Additionally, several measures were taken to assess the performance of the treatment. These measures included tracer test, pressure fall-off test, temperature survey, monitoring water and oil production, and monitoring wellhead pressures and injection rates. The results showed the increased oil production, reduced water production, improved fluid injection profile, shut-off of thief zone, no injectivity problems, favorable separation of surfactant/alcohol components, and significant delay in tracer breakthrough. Thus, the proposed method was effective in treating the permeability contrast problems.

Hochanadel and Townsend (1990) presented the results of a chemically-enhanced waterflood in Townsend Newcastle Sand Unit (TNSU) with a heterogeneous low-permeability $(40.5 \mathrm{mD})$ matrix (siltstone and very fine-grained sandstone). This field was depleted under solution gas drive with $13 \%$ OOIP recovery. The two main obstacles to flooding in TNSU are the presence of swelling (which limits the injectivity) and migrating clays and vertical fractures. The clay swelling forces all the injection into the fractures, causing premature water breakthrough and extremely poor sweep efficiency. Measures to overcome the waterflooding obstacles were to stabilize the clays at the injection wells, slow down the flow through the fractures and maximize the entry into the matrix by imbibition. Hence, to stabilize the clays, the near wellbore area of injection wells were treated with the $30 \mathrm{wt} . \%$ aqueous solution of $\mathrm{KOH}$ in 1986. Then, water injection began. The flow through the fractures was slowed down by using cationic and anionic polyacrylamides. Moreover, the imbibition in the matrix was promoted by using a wettability adjustment agent, consisting of a blend of anionic polymer and sodium tripolyphosphate (as an alkali). As a result, peak secondary producing rate was 1.25 times the peak primary rate. Also, the water-oil ratio reached unity in 1989. The $\mathrm{KOH}$ clay stabilization treatments were successful since the Hall Slope on an injection well that was not treated with $\mathrm{KOH}$ showed a damaged wellbore. The lowest Hall Slopes for the two injection wells near the fractures showed the lower resistance to flow in these two wells. This is why early water breakthrough through the fractures near these two wells was observed. Overall, the TNSU was a successful flood. A combination of clay stabilization and volumetric sweep improvement enhanced the recovery. Hochanadel and Townsend (1990) did not report the benefits of the wettability treatment in a quantitative fashion. However, it should be mentioned that the water-oil ratio of the field did not exceed unity until
1991. Thus, the wettability shift played an important role in prolonging the time to maintain a water-oil ratio of one.

DeHekker et al. (1986) reported two full-field PolymerAugmented Waterflood (PAW) in Wyoming's Big Horn Basin with pinpoint and vugular porosity and vertical fracturing. The project was designed to improve the sweep efficiency. Waterflooding in both fields was successful for the pressure maintenance, which allowed infill development. However, heterogeneities and high mobility ratios caused a large amount of bypassed oil. It was later inferred that some of these bypassed oil could be recovered with polymer flood. Polymer injectivity tests indicated that $1000 \mathrm{ppm}$ polymer could be injected without face plugging. PAW in Byron and North Oregon Basin significantly improved the oil recovery. Byron's incremental oil recovery of 163000 STB was reported due to tertiary PAW by 1986 . Also, $25 \%$ and $9 \%$ of the polymer were cycled through channels or fractures in Byron and North Oregon, respectively. It appeared that the polymer removed fines from the fractures. On one hand, many similarities exist between the PAW in Byron and North Oregon. In both fields, oil production rate and recovery increased. The polymer breakthrough, increased rod parting, and the increased injection pressures occurred in both fields. On the other hand, the tertiary oil response was more noticeable in North Oregon than in Byron, because of the more extensive fracture system and more severe cycling of polymer in Byron. Hence, the differences are as a result of the amount and degree of fracturing and permeability variances. Overall, it was found that the North Oregon is a more matrixdominated reservoir whereas Byron is more influenced by the presence of the fractures and imbibition mechanism.

Zornes et al. (1986) reviewed the North Burbank Unit (NBU) Block polymer flood in Oklahoma. Almost 52\% of OOIP had remained after primary and secondary recovery. To recover this residual oil, a small steam drive pilot was conducted in 1965 with disappointing results. NBU pilot polymer flooding, initiated in 1970 produced the incremental oil for 12 years. The NBU surfactant/polymer pilot, started in 1975 also produced some incremental oil. However, the economics of surfactant flooding in NBU was unfavorable in areas with extreme heterogeneity. Hence, polymer flooding was selected for a commercial expansion since it could improve the sweep efficiency in highly heterogeneous areas. Also, polymer flooding could improve both vertical and horizontal conformance. The high-permeability areas of this strongly oil-wet sandstone reservoir have the system of joints and/or fractures and high vertical permeabilities. The purpose of the polymer-aluminum citrate-polymer injection sequence was to cross-link the polymer molecules into a layered gel network resulting in higher values of mobility residual resistance factor. This process works in the fractures and high permeability zones for reducing the direct channeling of the injected fluids to the producers, which increases sweep efficiency. The NBU Block commercial polymer flooding was 
initiated in 1980, with the injection of fresh water preflush. The injection sequence was $500 \mathrm{ppm}$ active polymer augmented by $500 \mathrm{ppm}$ aluminum citrate cress-linking agent, $250 \mathrm{ppm}$ polymer, $50 \mathrm{ppm}$ polymer, fresh water post-flush, and finally the produced brine. An increase in wellhead pressure and an injectivity reduction indicated that the polymer flooding was building resistance to the flow in higher permeability zones, resulting in the increased sweep efficiency. Some wells experienced the polymer breakthrough very shortly, as an indicative of fractures. Also, some producing wells showed the decreased salinities within a short time of fresh water preflush, due to the presence of fractures. In summary, an economic production response occurred by the in-depth polymer-aluminum citrate-polymer process. The oil production rate in 1985 averaged over 30000 BOPD from a pre-project rate of less than $15000 \mathrm{BOPD}$. Also, the wateroil-ratio was reduced from over 100 to less than 50. Also, the aluminum citrate cross-linker helped to minimize the direct, early polymer flow to the producers. Thus, this project was economically and technically attractive in the heterogeneous NBU Block. It is noted that the reduced reservoir injectivity, which was observed, is normally expected in an expansion project. Thus, the polymer-aluminum citrate-polymer process can be utilized in similar fields with no significant near-well plugging.

\section{DISCUSSION AND SUMMARY}

The provided literature survey reveals that several fundamental aspects of the chemical flooding in NFRs have extensively been evaluated. In chemical flooding, the fluid inside fractures may displace the oil out of matrix by viscous displacement, capillary displacement, and gradual mass transfer. If enough aqueous chemical solution is supplied in fractures in a water-wet NFR, capillary imbibition may significantly contribute to the oil recovery. Hence, the key to recovering oil is the wettability alteration to preferentially water-wet condition. Anionic surfactants can be used to shift the wettability of carbonates towards intermediate/water-wet state. In absence of the emulsification-driven/capillary imbibition, then the gravity drainage may become the dominant mechanism. In gravity drainage, the surfactant molecules enter from fractures into the matrix via diffusion and convection. This changes the wettability and reduces the IFT. Consequently, gravitational forces overcome the entry capillary pressure and water invades the matrix and pushes the oil from the top. Furthermore, the injection of surfactant solution into oil-wet NFRs increases the oil relative permeability, enabling gravity to drain up the oil. Finally, since carbonate formations are normally positively charged; therefore nonionic and cationic surfactants are appropriate to reduce the surfactant adsorption. The alkali can also be used to reduce the surfactants adsorption.
Based upon chemical flooding pilot projects in NFRs, foremost factors have been identified in order to optimize the chemical flooding performance. The primary step to evaluate the efficiency in a large pilot or field is to run single well tests. Also, in order to reduce the water cut in the preferentially oil-wet NFRs, profile modification using cross linking gels is a possible candidate. The other suitable candidate might be treating wells with surfactant washes towards a large wettability alteration. Before performing any surfactant treatment, matrix stimulation might be necessary to further improve the near well-bore response. A wettability-shifting process like a surfactant-based chemical huff-n-puff process can also be carried out with different alkali/surfactant formulations. These two robust measures can reduce the water cut and improve the oil production. Finally, the main challenge of chemical flooding is the presence of fractures and vugs, which may prevent a uniform sweep and cause excessive chemical loss. Thus, to design the optimum slug size, chemical loss to the fractures must be taken into account. Moreover, to obtain high oil recovery, the chemical slug composition should be optimized.

The field projects of chemical flooding in NFRs have revealed several factors, which should be considered to design a successful flood. Several measures should be taken to assess the performance of chemical flooding. These include the tracer test, pressure fall-off test, temperature survey, monitoring water and oil production, and monitoring wellhead pressures and injection rates. In some NFRs, there exist problems associated with the clay swelling and migration and fractures. Clays swelling and migration limits injectivity and forces all the injected fluids into the fractures, causing premature breakthrough and poor sweep efficiency. The measures to overcome these obstacles are to stabilize the clays, to reduce the fracture flow, and to maximize the imbibition. To maximize the imbibition, pre-injecting alkali is an option. Also, another option is adding a wettability adjustment agent, such as a blend of an anionic polymer and an alkali. It is normally difficult to quantitatively measure the contribution of the wettability alteration in chemical flooding. However, it is believed that the wettability adjustment plays an important role in stabilizing a low water-oil ratio over a relatively long time.

Field-scale experiences of polymer flooding show that this process, if properly tailored to the reservoir condition, is an appropriate candidate for a NFR in which heterogeneities and high mobility ratios cause considerable oil bypassing. In addition, when the economics of surfactant flooding is unfavorable in the presence of extreme fracturing and heterogeneity, polymer flooding can be a candidate for a commercial project. In such cases, polymer flooding can significantly improve the oil recovery although there might be early polymer breakthrough. In particular, if a NFR is more matrix-dominated, then the performance of polymer flooding is more noticeable than that of a NFR influenced more by fractures with 
imbibition. The field projects have revealed several measures, which should be taken to design a successful flood. First, field test of polymer injectivity should be conducted to ensure injection without severe face plugging. A pressure fall-off test is also useful to assess any potential of near-well plugging problems. Second, care should be taken if polymer tends to cycle through channels or fractures. If polymer cycles through fractures and removes fines, then polymer breakthrough may cause tubular failure due to the entrained solids carried into the wellbore. In fact, oil recovery may decrease because of extensive polymer cycling. Finally, wellhead pressure should carefully be monitored during the flood. The reason is that an increase in wellhead pressure and an injectivity reduction may be an indicative factor that the resistance to flow is being built in higher permeability zones and macrofracture network. This increases the sweep efficiency.

The field projects of chemical flooding in NFRs have revealed the most effective methods to improve the sweep efficiency of chemical flooding in NFRs. One of the methods is the in-depth conformance control using the surfactant/ alcohol-based technology, which modifies the permeability in highly permeable zones. The surfactant-alcohol blends reduce the permeability contrast and divert the primary drive fluid to the target. The other method is the polymer-aluminum citrate-polymer injection sequence. This method works in the fractured zones for eliminating a direct channeling of injectants to the producers. The field experiences show that the aluminum citrate cross-linker can minimize the direct channeling of polymer to the producers.

\section{CONCLUSIONS}

- The fundamentals of the chemical flooding in NFRs have thoroughly been investigated. The key to recovering the oil is either the wettability shift towards water-wet condition to promote the capillary/emulsification-driven imbibition or the surfactant-aided gravity drainage;

- Single well tests, profile modification to reduce the water cut, wettability-shifting huff-n-puff processes, optimization of the slug composition and size, and chemical loss to fractures have to be considered to design a pilot project;

- The field projects have revealed several measures in order to assess the project performance. These include the tracer test, pressure fall-off test, temperature survey, monitoring water/oil production, wellhead pressures, and injection rates, and minimizing clay swelling and migration. To maximize the imbibition and stabilize a low water-oil ratio, pre-injecting alkali or a blend of an anionic polymer/ alkali for the wettability shift can be effective. Finally, in-depth conformance control by surfactant/alcohol injection, polymer-aluminum citrate-polymer injection sequence, and injecting cationic/anionic polymers combination help to improve the sweep efficiency;
- Field-scale polymer floodings show that this process can be appropriate for more matrix-dominated NFRs especially either for a NFR in which heterogeneities and high mobility ratios cause considerable oil bypassing or when the economics of surfactant flooding is unfavorable in presence of extreme fracturing. Field tests of polymer injectivity and pressure fall-off, and monitoring wellhead pressure and polymer cycling in fractures during the flood are necessary.

\section{ACKNOWLEDGMENT}

The author thanks Hamid Emami Meybodi at the University of Calgary, Canada, for providing a limited number of the articles on chemical flooding in Naturally Fractured Reservoirs used in this study.

\section{REFERENCES}

Abbasi-Asl Y., Pope G.A., Delshad M. (2010) Mechanistic Modeling of Chemical Transport in Naturally Fractured Oil Reservoirs, SPE Improved Oil Recovery Symposium, Tulsa, Oklahoma, USA, April 24-28.

Adibhatla B., Mohanty K.K. (2006) Oil Recovery from Fractured Carbonates by Surfactant-Aided Gravity Drainage: Laboratory Experiments and Mechanistic Simulations, SPE Symposium on Improved Oil Recovery, Tulsa, Oklahoma, USA, April 22-26.

Adibhatla B., Sun X., Mohanty K.K. (2005) Numerical Studies of Oil Production from Initially Oil-Wet Fracture Blocks by Surfactant Brine Imbibition, International Improved Oil Recovery Conference in Asia Pacific, Kuala Lumpur, Malaysia, December 5-6.

Aguilera R. (1987) Well Test Analysis of Naturally Fractured Reservoirs, SPE Formation Evaluation 2, 3, 239-252.

Aguilera R. (1995) Naturally Fractured Reservoir, PennWell Books, Tulsa, Oklahoma, USA

Aguilera R., Aguilera M.S. (2001) Well Test Analysis of MultiLayered Naturally Fractured Reservoirs with Variable Thickness and Variable Fracture Spacing, J. Can. Petrol. Technol. 40, 12, 9-12.

Aguilera C.G., Aguilera R. (2009) Effect of Fracture Dip on Petrophysical Evaluation of Naturally Fractured Reservoirs, J. Can. Petrol. Technol. 48, 7, 25-29.

Allan J., Qing Sun S. (2003) Controls on Recovery Factor in Fractured Reservoirs: Lessons Learned from 100 Fractured Fields, SPE Annual Technical Conference and Exhibition, Denver, Colorado, USA, October 5-8.

Austad T., Ekrann S., Fjelde I., Taugbol K. (1997) Chemical Flooding of Oil Reservoirs, Part 9. Dynamic Adsorption of Surfactant onto Sandstone Cores from Injection Water with and without Polymer Present, Colloid. Surface. A 127, 1-3, 69-82.

Babadagli T. (2001) Selection of Proper EOR Method for Efficient Matrix Recovery in Naturally Fractured Reservoirs, SPE Latin American and Caribbean Petroleum Engineering Conference, Buenos Aires, Argentina, March 25-28.

Babadagli T. (2001a) Scaling of Co-Current and Counter-Current Capillary Imbibition for Surfactant and Polymer Injection in Naturally Fractured Reservoirs, SPE J. 6, 4, 465-478.

Babadagli T. (2001b) Recovery of Heavy Matrix Oil by Capillary Imbibition in Naturally Fractured Reservoirs, SPE International Thermal Operations and Heavy Oil Symposium, Porlamar, Margarita Island, Venezuela, March 12-14. 
Babadagli T. (2002) Evaluation of EOR Methods for Heavy-Oil Recovery in Naturally Fractured Reservoirs, J. Petrol. Sci. Eng. 37, 1-2, 25-37.

Barenblatt G.E., Zheltov I.P., Kochina I.N. (1960) Basic Concepts in the Theory of Seepage of Homogeneous Liquids in Fissured Rocks, J. Appl. Math. Methods (USSR) 24, 1286-1303.

Bourbiaux B. (2010) Fractured Reservoir Simulation: a Challenging and Rewarding Issue, Oil Gas Sci. Technol. 65, 2, 227-238.

Bourbiaux B., Cacas M.C., Sarda S., Sabathier J.C. (1998) A Rapid and Efficient Methodology to Convert Fractured Reservoir Images into a Dual-Porosity Model, Oil Gas Sci.Technol. 53, 6, 784-799.

Bourbiaux B., Kalaydjian F. (1990) Experimental Study of Cocurrent and Countercurrent Flows in Natural Porous Media, SPE Reserv. Eval. Eng. 5, 3, 361-368.

Chen H.L., Lucas L.R., Nogaret L.A.D., Yang H.D., Kenyon D.E. (2000) Laboratory Monitoring of Surfactant Imbibition Using Computerized Tomography, International Petroleum Conference and Exhibition, Villahermosa, Mexico, February 1-3.

Da Prat G. (1990) Well Test Analysis for Fractured Reservoir Evaluation, Elsevier, Amsterdam, The Netherlands.

Daoshan L., Shouliang L., Yi L., Demin W. (2004) The Effect Of Biosurfactant on the Interfacial Tension and Adsorption Loss of Surfactant in ASP Flooding, Colloid. Surface. A 244, 1-3, 53-60.

DeHekker T.G., Bowzer J.L., Coleman R.V., Bartos W.B. (1986) A Progress Report on Polymer-Augmented Waterflooding in Wyoming's North Oregon Basin and Byron Fields, SPE/DOE Fifth Symposium on Enhanced Oil Recovery, Tulsa, Oklahoma, USA, April 20-23.

Donaldson E.C., Chilingarian G.V., Yen T.F. (1989) Enhanced Oil Recovery, II: Processes and Operations (Developments in Petroleum Science), Elsevier Science Ltd.

Dong H., Hong Y., Rui W. (2006) The Effect of Wettability on Oil Recovery of Alkaline/Surfactant/Polymer Flooding, SPE Annual Technical Conference and Exhibition, San Antonio, Texas, USA, September 24-27.

Downs H.H., Hoover P.D. (1989) Oil Field Chemistry: Enhanced Recovery and Production Stimulation, ACS Symposium Series 396, American Chemical Society, Washington DC, USA.

Dullien F.A.L., Dhawan G.K., Gurak N., Babjak L. (1972) A Relationship between Pore Structure and Residual Oil Saturation in Tertiary Surfactant Floods, SPE J. 12, 4, 289-296.

Enedy S.L., Farouq Ali S.M., Stahl C.D. (1982) Competing Roles of Interfacial Tension and Surfactant Equivalent Weight in the Development of a Chemical Flood, SPE J. 22, 4, 503-513.

Firoozabadi A. (2000) Recovery Mechanisms in Fractured Reservoirs and Field Performance, J. Can. Petrol. Technol. 39, 11, 13-17.

Firoozabadi A., Thomas L.K. (1990) Sixth SPE Comparative Solution Project: Dual-Porosity Simulators, J. Petrol. Technol. 42, 710-715.

Friedmann F. (1986) Surfactant and Polymer Losses during Flow through Porous Media, SPE Reserv. Eng. 1, 3, 261-271.

Gasem F.H., Nashawi I.S., Gharbi R., Mir M.I. (2008) Recovery Performance of Partially Fractured Reservoirs by Capillary Imbibition, J. Petrol. Sci. Eng. 60, 1, 39-50.

Ghorayeb K., Firoozabadi A. (2000) Numerical Study of Natural Convection and Diffusion in Fractured Porous Media, SPE J. 5, 1, $12-20$

Gilman J., Kazemi H. (1983) Improvements in Simulation of Naturally Fractured Reservoirs, SPE J. 23, 4, 695-707.

Gilman J., Kazemi H. (1988) Improved Calculations for Viscous and Gravity Displacement in Matrix Blocks in Dual-Porosity Simulators, J. Petrol. Technol.40, 1, 60-70.
Glover C.J., Puerto M.C., Maerker J.M., Sandvik E.L. (1979) Surfactant Phase Behavior and Retention in Porous Media, SPE J. 19, 3, 183-193.

Gupta R., Mohan K., Mohanty K.K. (2009) Surfactant Screening for Wettability Alteration in Oil-Wet Fractured Carbonates, SPE Annual Technical Conference and Exhibition, New Orleans, Louisiana, USA, October 4-7.

Gupta R., Mohanty K.K. (2008) Wettability Alteration of Fractured Carbonate Reservoirs, SPE/DOE Symposium on Improved Oil Recovery, Tulsa, Oklahoma, USA, April 20-23.

Handy L.L., Amaefule J.O., Ziegler V.M., Ershaghi I. (1982) Thermal Stability of Surfactants for Reservoir Application, SPE J. 22, 5, 722-730.

Hayes M.E., Bourrel M., El-Emary M.M., Schechter R.S., Wade W.H. (1979) Interfacial Tension and Behavior of Nonionic Surfactants, SPE J.19, 6, 349-356.

Hirasaki G.J. (1981) Application of the Theory of Multicomponent, Multiphase Displacement to Three-Component, Two-Phase Surfactant Flooding, SPE J. 21, 2, 191-204.

Hirasaki G.J. (2008) Recent Advances in Surfactant EOR, SPE Annual Technical Conference and Exhibition, Denver, Colorado, USA, September 21-24.

Hirasaki G.J., van Domselaar H.R., Nelson R.C. (1983) Evaluation of the Salinity Gradient Concept in Surfactant Flooding, SPE J. 23, $3,486-500$.

Hirasaki G.J., Zhang D.L. (2004) Surface Chemistry of Oil Recovery from Fractured, Oil-Wet, Carbonate Formations, SPE J. 9, 2, 151-162.

Hochanadel S.M., Townsend C.L. (1990) Improving Oil Recovery in the Naturally Fractured, Tight, Dirty Sandstone of the Townsend Newcastle Sand Unit, Weston County, Wyoming, CIM/SPE International Technical Meeting, Calgary, Alberta, Canada, June $10-13$.

Huh C. (1979) Interfacial Tensions and Solubilizing Ability of a Microemulsion Phase that Coexists with Oil and Brine, J. Colloid Interf. Sci. 71, 2, 408-426.

Kazemi H., Gilman J.K., Elsharkawy A.M. (1992) Analytical and Numerical Solution of Oil Recovery from Fractured Reservoirs with Empirical Transfer Function, SPE Reserv. Eng. J. 7, 2, 219-227.

Kazemi H., Merrill L.S., Porterfield K.L., Zeman P.R. (1976) Numerical Simulation of Water-Oil Flow in Naturally Fractured Reservoirs, SPE J. 16, 6, 317-326.

Krumrine P.H. (1982) Mechanisms of Retention in Silicate Enhanced Dilute Surfactant Low Tension Floods, SPE 6th International Symposium on Oilfield; and Geothermal Chemistry, Dallas, Texas, USA, January 25-27.

Krumrine P.H., Falcone J.S., Campbell T.C. (1982) Surfactant Flooding 1: The Effect of Alkaline Additives on IFT, Surfactant Adsorption, and Recovery Efficiency, SPE J.22, 4, 503-513.

Landereau P., Noetinger B., Quintard M. (2001) Quasi-Steady TwoEquation Models for Diffusive Transport in Fractured Porous Media: Large-Scale Properties for Densely Fractured Systems, $A d v$. Water Resour. 24, 8, 863-876.

Lemonnier P., Bourbiaux B. (2010a) Simulation of Naturally Fractured Reservoirs. State of the Art - Part 1 - Physical Mechanisms and Simulator Formulation, Oil Gas Sci. Technol. 65, 2,239-262.

Lemonnier P., Bourbiaux B. (2010b) Simulation of Naturally Fractured Reservoirs. State of the Art - Part 2 - Matrix-Fracture Transfers and Typical Features of Numerical Studies, Oil Gas Sci. Technol. 65, 2, 263-286.

Li D., Shi M., Wang D., Li Z. (2009) Chromatographic Separation of Chemicals in Alkaline Surfactant Polymer Flooding in Reservoir Rocks in the Daqing Oilfield, SPE International Symposium on Oilfield Chemistry, Woodlands, Texas, USA, April 20-22. 
Lim K.T., Aziz K. (1995) Matrix-Fracture Transfer Shape Factors for Dual-Porosity Simulators, J. Petrol. Sci. Eng. 13, 169-178.

Liu Q., Dong M., Ma S. (2006) Alkaline/Surfactant Flood Potential in Western Canadian Heavy Oil Reservoirs, SPE/DOE Symposium on Improved Oil Recovery, Tulsa, Oklahoma, USA, April 22-26.

Llave F.M., Dobson R.E. (1994) Field Application of SurfactantAlcohol Blends for Conformance Control, SPE Annual Technical Conference and Exhibition, New Orleans, Louisiana, USA, September 25-28.

Long J.C.S., Gilmour P., Witherspoon P.A. (1985) A Model for Steady Fluid Flow in Random Three-Dimensional Networks of Disc-Shaped Fractures, Water Resour. Res. 21, 8, 1105-1115.

Lu H., Di Donato G., Blunt M.J. (2008) General Transfer Functions for Multiphase Flow in Fractured Reservoirs, SPE J. 13, 3, 289-297.

Ma S., Dong M., Li Z., Shirif E. (2007) Evaluation Of The Effectiveness of Chemical Flooding Using Heterogeneous Sandpack Flood Test, J. Petrol. Sci. Eng. 55, 3-4, 294-300.

Morrow N.R. (1990) Wettability and Its Effect on Oil Recovery, J.Petrol.Technol. 42, 12, 1476-1484.

Morrow N.R., Songkran B. (1981) Effect of Viscous and Buoyancy Forces on Nonwetting Phase Trapping in Porous Media, in Surface Phenomena in Enhanced Oil Recovery, Shah D.O. (ed.), Plenum Press, pp. 387-411.

Najafabadi N.F., Delshad M., Sepehrnoori K., Nguyen Q.P., Zhang J. (2008) Chemical Flooding of Fractured Carbonates Using Wettability Modifiers, SPE/DOE Improved Oil Recovery Symposium, Tulsa, Oklahoma, USA, April 20-23.

Nelson R.A. (1985) Geologic Analysis of Naturally Fractured Reservoirs, Gulf Publishing Company, Houston, Texas, USA.

Novosad J. (1982) Surfactant Retention in Berea Sandstone Effects of Phase Behavior and Temperature, SPE J. 22, 6, 962-970.

Peaceman D.W. (1976a) Convection in Fractured Reservoirs - The Effect of Matrix-Fissure Transfer on the Instability of a Density Inversion in a Vertical Fissure, SPE J. 16, 5, 269-280.

Peaceman D.W. (1976b) Convection in Fractured Reservoirs Numerical Calculation of Convection in a Vertical Fissure, Including the Effect of Matrix-Fissure Transfer, SPE J. 16, 5, 281-301.

Penell K.D., Pope G.A., Abriola L.M. (1996) Influence of Viscous and Buoyancy Forces on the Mobilization of Residual Tetrachloroethylene during Surfactant Flushing, Environ. Sci. Technol. 30, 4, 1328-1335.

Ramirez W.F., Shuler P.J., Friedman F. (1980) Convection, Dispersion, and Adsorption of Surfactants in Porous Media, SPE J. 20, 6, 430-438.

Reiss L.H. (1980) The Reservoir Engineering Aspects of Fractured Formations, Editions Technip, Paris.

Roehl P.O., Choquette P.W. (1985) Carbonate Petroleum Reservoirs, Springer-Verlag.

Rossen R.H. (1977) Simulation of Naturally Fractured Reservoirs with Semi Implicit Source Terms, SPE J. 17, 3, 201-210.

Rossen R.H., Shen E.I.C. (1989) Simulation of Gas/Oil Drainage and Water/Oil Imbibition in Naturally Fractured Reservoirs, SPE Reserv. Eng. 4, 4, 464-470.

Sarma P., Aziz K. (2006) New Transfer Functions for Simulation of Naturally Fractured Reservoirs with Dual-Porosity Models, SPE J. 11, 3, 328-340.

Saidi A.M. (1983) Simulation of Naturally Fractured Reservoirs, SPE Reservoir Simulation Symposium, San Francisco, USA, November 15-18.

Saidi A.M. (1987) Reservoir Engineering of Fractured Reservoirs (fundamental and practical aspects), TOTAL Edition Press, Paris, France.
Salager J.L., Morgan J.C., Schechter R.S., Wade W.H. Vasquez E. (1979) Optimum Formulation of Surfactant/Water/Oil Systems for Minimum Interfacial Tension or Phase Behavior, SPE J. 19, 2, 107-115.

Seethepalli A., Adibhatla B., Mohanty K.K. (2004) Physicochemical Interactions During Surfactant Flooding of Fractured Carbonate Reservoirs, SPE J.9, 4, 411-418.

Shad S., Gates I.D. (2010) Multiphase Flow in Fractures: Co-Current and Counter-Current Flow in a Fracture, J. Can. Petrol. Technol. 49, 2, 48-55.

Shah D.O. (1981) Surface Phenomena in Enhanced Oil Recovery, Plenum Press, New York City, USA.

Shah D.O., Schechter R.S. (1977) Improved Oil Recovery by Surfactant and Polymer Flooding, Academic Press, New York City, New York, USA.

Somasundaran P., Celik M., Goyal A., Manev E. (1984) The Role of Surfactant Precipitation and Redissolution in the Adsorption of Sulfonate on Minerals, SPE J. 24, 2, 233-239.

Standnes D.C., Austad T. (2000) Wettability Alteration in Chalk: 2. Mechanism for Wettability Alteration from Oil-Wet to Water-Wet Using Surfactants, J. Petrol. Sci. Eng. 28, 3, 123-143.

Tang G.-Q., Firoozabadi A. (2000) Effect of Viscous Forces and Initial Water Saturation on Water Injection in Water-Wet and Mixed-Wet Fractured Porous Media, SPE/DOE Improved Oil Recovery Symposium, Tulsa, Oklahoma, USA.

Tweheyo M.T., Zhang P., Austad T. (2006) The Effects of Temperature and Potential Determining Ions Present in Seawater on Oil Recovery from Fractured Carbonates, SPE Symposium on Improved Oil Recovery, Tulsa, Oklahoma, USA, April 22-26.

Van Golf-racht T.D. (1982) Fundamentals of Fractured Reservoir Engineering, Elsevier, Amsterdam, The Netherlands.

van Poollen H.K. (1981) Fundamentals of Enhanced Oil Recovery, PennWell Publishing Company, Tulsa, Oklahoma, USA.

Warren J.E., Root P.J. (1963) The Behavior of Naturally Fractured Reservoirs, SPE J. 3, 3, 245-255.

Weiss W.W., Xie X. (2007) Oilfield Surfactants Improve Recovery by Imbibition, International Symposium on Oilfield Chemistry, Houston, Texas, USA, February 28-March 2.

Wu Y.-S., Liu H.H., Bodvarsson G.S. (2004) A Triple Continuum Approach for Modeling Flow and Transport Processes in Fractured Rock, J. Contam. Hydrol. 73, 1-4, 145-179.

Xie X., Weiss W.W., Tong Z., Morrow N.R. (2005) Improved Oil Recovery from Carbonate Reservoirs by Chemical Stimulation, SPE J.10, 3, 276-285.

Yadali Jamaloei B. (2007) Experimental Study of Surfactant/ Water/Polymer Flooding Using One-Quarter Five-Spot Glass Micromodels, M.Sc. Thesis, Petroleum University of Technology, Tehran, Iran.

Yadali Jamaloei B. (2009) Insight into the Chemistry of Surfactantbased Enhanced Oil Recovery Processes, Recent Patents Chem. Eng. 2, 1, 1-10.

Yadali Jamaloei B., Ahmadloo F., Kharrat R. (2010a) The Effect of Pore Throat Size and Injection Flowrate on the Determination and Sensitivity of Different Capillary Number Values at High-CapillaryNumber Flow in Porous Media, Fluid Dyn. Res. 42, 5, 055505.

Yadali Jamaloei B., Asghari K., Kharrat R., Ahmadloo F. (2010b) Pore-scale Two-Phase Filtration in Imbibition Process through Porous Media at High- and Low-Interfacial Tension Flow Conditions, J. Petrol. Sci. Eng. 72, 3-4, 251-269.

Yadali Jamaloei B., Asghari K., Kharrat R., (2011a) Pore-Scale Flow Characterization of Low-Interfacial Tension Flow through Mixed-Wet Porous Media with Different Pore Geometries, Exp. Therm. Fluid Sci.35, 1, 253-264. 
Yadali Jamaloei B., Kharrat R. (2009) Fundamental Study of Pore Morphology Effect in Low Tension Polymer Flooding or PolymerAssisted Dilute Surfactant Flooding, Transport Porous Med. 76, 2, 199-218.

Yadali Jamaloei B., Kharrat R. (2010a) Analysis of Microscopic Displacement Mechanisms of Dilute Surfactant Flooding in Oil-Wet and Water-Wet Porous Media, Transport Porous Med. 81, 1, 1-19.

Yadali Jamaloei B., Kharrat R. (2010b) Analysis of Pore-Level Phenomena of Dilute Surfactant Flooding in the Presence and Absence of Connate Water Saturation, J. Porous Media 13, 8, 671-690.

Yadali Jamaloei B., Kharrat R. (2011) Lessons Learned from the Miscible Gas Flooding in Naturally Fractured Reservoirs: Integrated Studies, and Pilot and Field Cases, Petrol. Sci. Technol. (in print).

Yadali Jamaloei, B., Kharrat, R., Torabi, F. (2011b) Analysis and Correlations of Viscous Fingering in Low-Tension Polymer Flooding in Heavy Oil Reservoirs, Energ. Fuel., DOI: 10.1021/ef101061b.

Yang H.D., Wadleigh E.E. (2000) Dilute Surfactant IOR - Design Improvement for Massive, Fractured Carbonate Applications, SPE International Petroleum Conference and Exhibition, Villa Hermosa, Mexico, February 1-3.
Zhang D. (2007) Surfactant-Enhanced Oil Recovery Process for a Fractured, Oil-Wet Carbonate Reservoir, PhD Dissertation, Rice University, Houston, Texas, USA.

Zhang D.L., Liu S., Puerto M., Miller C.A., Hirasaki G.J. (2006) Wettability Alteration and Spontaneous Imbibition in Oil-Wet Carbonate Formations, J. Petrol. Sci. Eng. 52, 1-4, 213-226.

Zhang J., Nguyen Q.P., Flaaten A.K., Pope G.A. (2008) Mechanisms of Enhanced Natural Imbibition with Novel Chemicals, SPE/DOE Improved Oil Recovery Symposium, Tulsa, Oklahoma, USA, April 20-23.

Zornes D.R., Cornelius A.J., Long H.Q. (1986) An Overview and Evaluation of the North Burbank Unit Block: A Polymer Flood Project, Osage County, Oklahoma, SPE International Meeting on Petroleum Engineering, Beijing, China, March 17-20.

Zubari H.k., Sivakumar V.C.B. (2003) Single Well Tests to Determine the Efficiency of Alkaline-Surfactant Injection in a Highly Oil-Wet Limestone Reservoir, SPE Middle East Oil and Gas Show and Conference, Bahrain, June 9-12.

Final manuscript received in December 2010 Published online in May 2011 